Conclusions Death cafes proved to be an effective tool for staff development and increased healthcare professionals' confidence in discussing death. We will now expand this through using a similar format as an educational tool with medical students. The sessions will focus on training in end of life care; the process will be evaluated in terms of design and learning gain. The results will be available for the conference.

\section{FOUNDATION YEAR 1 (FY1) DOCTORS KNOWLEDGE ABOUT COMMON PALLIATIVE MEDICINE PRESCRIBING ISSUES}

Kate Holyhead, Rachel Bullock, Derek Willis. Univesity Hospital, Coventry and Warwickshire, Severn Hospice

\subsection{6/bmjspcare-2018-ASPabstracts.41}

Background Death and the process of dying is an inevitable part of the practice of medicine. The ability to provide palliative care is a necessity for every junior doctor and currently approximately $60 \%$ of deaths occur in hospital. It has been suggested that current undergraduate medical education is failing to prepare junior doctors for their role in caring for dying patients. Dealing with death and talking to distressed relatives is also a major source of stress. This study aims to explore and describe the type and amount of undergraduate palliative medicine education received; to explore and describe the participant's level of confidence towards the management of patients with palliative care needs and to assess the level of prescribing knowledge when faced with common palliative care scenarios.

Methods Mixed methods questionnaires including case vignettes with single-best answer, multiple choice questions were completed under exam conditions by newly qualified junior doctors.

Results 37 FY1 doctors were included in the study. The mean time allocated to undergraduate teaching was 21 hours with a wide range of $2-140$ hours. A palliative clinical placement was a component of teaching in $41 \%$ of participants. Participantreported confidence levels varied among the four areas explored but the majority of participants responded negatively. The mean score of the knowledge component of the questionnaire was $45 \%$ (range 20\%-80\%). Level of participantreported confidence demonstrated no correlation with knowledge as assessed.

Conclusions This study highlights the lack of exposure of undergraduates to patients with palliative care needs, a variable level of knowledge when faced with scenarios they are likely to encounter during foundation years, and a level of confidence in the subject which may not correlate with their practical abilities.

\section{VARIANCE IN SELF-REPORTED OPIOID PRESCRIBING PRACTICES BY JUNIOR DOCTORS AT A DISTRICT GENERAL HOSPITAL: IMPLICATIONS FOR MEDICAL EDUCATION}

HK Crispin, N Heron. West Midlands Deanery, Worcestershire Acute Hospitals Trust

\subsection{6/bmjspcare-2018-ASPabstracts.42}

Introduction Opioids are commonly prescribed by Junior Doctors in the acute hospital setting. Here we describe the self- reported behaviour of this professional group in relation to opioid prescribing for palliative in-patients at a District General Hospital.

Method A structured survey was completed by twenty-seven training grade doctors from F1-CT3 $(85.2 \% \mathrm{~F} 1$ or F2). The anonymous responses related to self-reported behaviour based on recall of patient care episodes.

Results Two thirds of respondents were involved in the care of palliative patients on a weekly basis. Therefore, the prescribing of opioids and evaluation of treatment efficacy should be embedded into their practice.

When monitoring the side-effects of opioid therapy, patients may not automatically declare these, so it is advisable to directly enquire. Seventy-three percent of respondents reported that they do so for less than half of their patients. Constipation and nausea were reported as most likely to be assessed; being ascertained at least half of the time by ninety-six percent and eighty-five percent of respondents, respectively. None of the respondents routinely enquired about bad dreams, myoclonic jerks or hallucinations.

The occurrence of opioid-associated side effects, or the absence of these, are crucial findings to document in the medical record. Forty-five percent of respondents reported that they do not always document when a patient is experiencing side-effects from opioid therapy. Forty-eight percent of respondents reported that they never document the absence of opioid-associated side effects.

Conclusion This account indicates scope for improvement in the monitoring and documentation of side effects associated with opioid therapy by the Junior Doctors at this District General Hospital. These findings highlight a need for education of this staff group at a local level, and may well indicate a need for enhanced education in opioid prescribing in Medical Undergraduate Curricula.

\section{DECISIONS AND DISCUSSIONS RELATING TO DNACPR IN A REGIONAL CANCER CENTRE}

Ann Griffiths, Daniel Monnery, Alison Coackley, Amanda Watson, Sinead Benson, Claire Cadwallader, Malcom Cooper. The Clatterbridge Cancer Centre

10.1136/bmjspcare-2018-ASPabstracts.43

Background In 2014 the family of a woman who died in one of Britain's best-known hospitals won their legal claim that her rights were violated when a Do Not Attempt Cardiopulmonary Resuscitation (DNACPR) document was completed without her or her family being consulted.

A judicial review noted that Article 8 of the Human Rights Act was breached, concluding that there is a duty to consult patients and/or those important to them in relation to DNACPR unless that consultation may result in physical or psychological harm; this is more than just causing distress.

Aim Audit practice regarding DNACPR decisions and the discussions surrounding them in a tertiary cancer centre.

Methods A retrospective case note review of patients' in whom a DNACPR had been placed was conducted in December 2016. Practice was compared against the 2016 Joint Statement, 'Decisions relating to cardiopulmonary resuscitation'.

Results 22 case notes were reviewed in which a DNACPR was completed; 19 due to futility in cases of terminal cancer and 3 due to patient choice. In 3 cases no consultation had taken place. The reasons for this included patient/family declining a 